\title{
Temperature effect on luteinizing hormone secretion of Eurasian Skylark (Alauda arvensis) and Great Tit (Parus major) in China
}

\author{
Lijun $\mathrm{Gao}^{\dagger}$, Jing Gao ${ }^{\dagger}$ and Shuping Zhang ${ }^{*}$
}

\begin{abstract}
Background: Global warming caused trophic mismatch has affected the breeding success, and even the survival, of some bird species. The ability of birds to accelerate their reproduction onset in the warmer spring could be critical to the survival of some species. The activation of the reproductive endocrine axis in birds is a key physiological process that determines the onset of reproduction. Could birds change the HPG axis endocrine rhythm under the temperature rising condition?
\end{abstract}

Methods: Using plasma LH level as an indicator of initiation of the reproductive endocrine and artificially controlling temperature, we compared variations in the timing of activation of the reproductive endocrine axis in response to temperature in two Chinese bird species, the Eurasian Skylark (Alauda arvensis) and the Great Tit (Parus major) at both the population and individual levels.

Results: At the population level, temperature only significantly influenced LH level in the Eurasian Skylark, and had no significant effect on the LH levels in the Great Tit. Mean LH level of Eurasian Skylarks in the $20^{\circ} \mathrm{C}$ group was higher than that of those in the $15^{\circ} \mathrm{C}$ group throughout the experiment. Large individual variations in the timing of peak $\mathrm{LH}$ levels were observed in the high and the low temperature groups of both Eurasian Skylarks and Great Tits.

Conclusions: These results indicate that the effects of temperature differ among species. Meanwhile, there appears to be a degree of within population polymorphism in the timing of reproductive endocrine axis activation in some species. This polymorphism could provide the variation required for bird populations to cope with the possible change of their food peak under the climate warming condition.

Keywords: Reproductive endocrine rhythm, Temperature, Climate warming, Eurasian Skylark, Great Tit

\section{Background}

In mid to high latitude areas, birds use reliable environmental cues to anticipate the onset of predictable environmental change (Dawson et al. 2001). Change in photoperiod is both entirely predictable and closely related to local food availability, both within and among years. For this reason, photoperiod is the most important physiological cue for reproduction in birds (Wingfield 1993; Dawson et al. 2001; Gwinner 2003). Variation in photoperiod controls the initiation of reproduction

\footnotetext{
*Correspondence: zhangshuping@muc.edu.cn

${ }^{\dagger}$ Lijun Gao and Jing Gao contributed equally to this work

College of Life and Environment Sciences, Minzu University of China, Beijing 100081, China
}

through the hypothalamus-pituitary-gonad (HPG) axis. In spring, an increase in photoperiod leads to elevated secretion of gonadotrophin-releasing hormone-I (GnRH-I) from the median eminence at the base of the hypothalamus (Yamamura et al. 2006). This stimulates the synthesis and release of luteinizing hormone (LH) and follicle-stimulating hormone (FSH) in the pituitary (Pawson and McNeilly 2005). These two hormones are secreted into the blood and induce gonadal maturation which initiates reproductive behavior (Dawson 2008). Many birds rely on the availability of insects to feed their nestlings. By advancing the onset of warmer temperatures but not photoperiod, climate warming has caused the emergence of insects and the start of the 
avian breeding cycle to become asynchronous (Cotton 2003; Both et al. 2006, 2010; Visser et al. 2006, 2012). The resultant trophic mismatch between the peak of insect emergence and the avian reproductive cycle affects the breeding success, and in some cases, the survival of some bird species (Cotton 2003; Visser et al. 2006; Both et al. 2006, 2010; Gullett et al. 2013). Therefore the ability of birds to change their reproduction rhythm under warmer condition determines their future probability of survival.

Several studies have tested the ability of birds to change the initiation of reproductive endocrine axis in response to ambient temperature variation. The results show that the capacity to do this differs among species, among local populations of the same species, and between males and females. For example, although exposure to high temperature can enhance follicular development in the female White-crowned Sparrow (Zonotrichia leucophrys pugetensis) (Wingfield et al. 1997) and testicular growth rate and LH secretion in the Great Tit (Parus major; Silverin et al. 2008), temperature had no effect on testicular development in male White-crowned Sparrows (Wingfield et al. 1997) or Common Starlings (Sturnus vulgaris; Dawson 2005), testicular development and LH secretion in two Scandinavian populations of Great Tits (Silverin et al. 2008), or LH secretion in the Mountain Whitecrowned Sparrow (Z. l. oriantha; Wingfield et al. 2003). To shed further light on the effect of temperature on the activation of the reproduction endocrine axis, more bird species living at mid or high latitudes should be tested against the background of climate warming.

On the other hand, physiologists are in general less interested in variation among individuals (Wingfield et al. 1992; Ball and Balthazart 2008; Williams 2008), than in that between-species or between-populations. Phenotypic polymorphism exists within populations, and this variation may provide the basis for populations to adapt to environmental variation. From this perspective, individual variation in the timing of HPG axis activation reflects the capacity of populations to cope with the challenge of climate warming.

In this paper, we hypothesized that higher temperature could accelerate the activation of HPG axis of birds and the individual variation on HPG axis endocrine rhythm should exist in the population of mid to high latitude birds. To test this hypothesis, we compared the photoperiod induced LH secretion rhythms of Eurasian Skylark (Alauda arvensis) and Great Tit (Parus major) in two temperature conditions at the population and individual levels.

\section{Methods}

\section{Species in the study}

The Eurasian Skylark is a common grassland species in northeast China, which is a cold temperate, high latitude area. The Great Tit is found in the broadleaf forests of north China, which is a warm temperate, mid-latitude area. The Eurasian Skylarks used in our experiments were captured at Hulunbell $\left(47^{\circ} 45^{\prime} \mathrm{N}, 116^{\circ} 50^{\prime} \mathrm{E}\right)$, and the Great Tits were at Beijing $\left(39^{\circ} 48^{\prime} \mathrm{N}, 115^{\circ} 25^{\prime} \mathrm{E}\right)$. All samples were collected with the permission of the Forestry Bureau of the local governments.

\section{Experimental design}

All birds used in the experiment were adults captured in February 2012. The body mass of two species are $34.13 \pm 0.1 \mathrm{~g}$ (Eurasian Skylark) and $15 \pm 0.16 \mathrm{~g}$ (Great Tit) respectively. Individuals of each species were kept in separate aviaries (one bird in one cage) and individually identified with numbered leg bands. Two artificially temperature and light controlled rooms were established. The temperature treatments were set as 15 and $20^{\circ} \mathrm{C}$, in which $15{ }^{\circ} \mathrm{C}$ was based on the average maximum daily temperatures recorded at the sample site of each bird species during the months the two species initiate reproduction, and $20{ }^{\circ} \mathrm{C}$ was the higher temperature compared to the $15^{\circ} \mathrm{C}$. Birds were randomly assigned to one of two temperature groups. The $15{ }^{\circ} \mathrm{C}$ group was comprised of 10 Great Tits and 13 Eurasian Skylarks, while the $20^{\circ} \mathrm{C}$ group was comprised of 10 Great Tits and 12 Eurasian Skylarks. Birds were fed mixed seeds, boiled eggs and meal worms, and provided with water, during the experiment.

All birds were acclimatized to captivity and subjected to a short photoperiod (8L: 16D) for 1 month before the experiment began. The photoperiod of all groups was then lengthened by $2 \mathrm{~h}$ per week until the experiment concluded after 5 weeks, which is designed to mimic the chronic nature day time length variation in spring. All birds received the same food and water and were blooded on the first day of each long light treatment week. Some $50 \mu \mathrm{L}$ whole blood was collected by puncturing a brachial wing vein with a disinfected $23 \mathrm{G}$ needle. The skin around the puncture site was disinfected with medical grade alcohol before and after puncturing. Pressure was applied to the puncture site for $1 \mathrm{~min}$ with an alcoholsoaked cotton wool swab to staunch bleeding. Blood samples were stored at $4{ }^{\circ} \mathrm{C}$ for up to $8 \mathrm{~h}$ until centrifuged at $3000 \mathrm{r} / \mathrm{min}$ for $10 \mathrm{~min}$. The resultant blood plasma and blood cells were then kept frozen in micro-centrifuge tubes until assayed. Blood plasma was used to measure plasma LH concentration. Each bird was sexed from DNA extracted from blood cells according to the method described by Griffith et al. (1999).

Experimental procedures conformed to the relevant Chinese laws and had the approval of Hainan Normal University's Animal Research Ethics Committee. In addition, all procedures followed standard protocols, such as the ARRIVE guidelines for reporting animal research. 


\section{Hormone assay}

Plasma LH levels were measured using chicken enzyme immunoassay kits from MyBioSource (cat\#MBS165746), which had been validated previously by our laboratory for use on Tree Sparrows (Passer montanus; Zhang et al. 2014), Asian Short-toed Lark (Calandrella cheleensis) and Eurasian Skylark (Zhao et al. 2017). We used the method described by Chastel et al. (2005) to confirm that the kits would work on the two species in this study. Briefly, the plasma samples from 20 birds of each species were pooled and diluted by $1,1 / 2,1 / 4,1 / 8,1 / 16$ and $1 / 32$, then we used the kits to analyze the concentration-dependent binding dynamics of the diluted samples of each species and draw a dilution VS B/Bo curve for each species. If the dilution VS B/Bo curves were parallel to the standard solution VS B/Bo curve (their slopes being not significantly different), the kit can be reliably used on the species. The dilution curves of the two species in our study were parallel to the standard solution VS B/Bo curve (slope: Chicken 2.35, Great Tit 2.32, Eurasian Skylark 2.33; Additional file 1: Figure S1), confirming that the kits could assess levels of $\mathrm{LH}$ of the two species. The respective inter- and intraplate coefficients of variation for LH were 7.01 and $6.2 \%$, respectively.

\section{Data analysis}

Differences in plasma LH levels between the different temperature treatment groups of each species were analyzed with a Linear Mixed Model (LMM) in which temperature, sex, treatment week, and the interactions between these factors were modeled as fixed factors, and individual bird was included as a random factor. Plasma LH concentrations were log transformed to correct for departures from normality and homogeneity of variance. $p$ values $<0.05$ were considered significant. All data analyses were performed in SPSS 18.0.

\section{Results}

\section{Effect of temperature on plasma LH}

The results of the LMM for Eurasian Skylark indicate that treatment week and temperature significantly influenced the LH concentration of Eurasian Skylarks, whereas sex and all interaction terms were insignificant (Table 1). Mean plasma LH of the Eurasian Skylarks in $20{ }^{\circ} \mathrm{C}$ group were significantly higher than those in $15{ }^{\circ} \mathrm{C}$ group in the first ( $T$ test, $n=12, p=0.037$ ), second ( $T$ test, $n=12, p<0.001$ ) and third ( $T$ test, $n=12$, $p<0.001$ ) experimental weeks (Fig. 1a). However, the LMM results indicate that only treatment week significantly influenced LH concentration of Great Tit, and that temperature, sex and all interaction terms were insignificant (Fig. 1b, Table 1).
Table 1 Results of a linear mixed model of the effects of week, sex, and temperature on plasma LH concentrations in Eurasian Skylark and Great Tit

\begin{tabular}{|c|c|c|c|c|}
\hline Species & Explanatory variable & df & $F$ & $p$ \\
\hline \multirow[t]{7}{*}{ Eurasian Skylark } & Week & 5,124 & 8.331 & $<0.001$ \\
\hline & Sex & 1,124 & 1.212 & 0.325 \\
\hline & Temperature & 1,124 & 6.578 & 0.045 \\
\hline & Week $^{*}$ sex & 5,124 & 0.420 & 0.833 \\
\hline & Week* temperature & 5,124 & 0.159 & 0.977 \\
\hline & Sex $*$ temperature & 1,124 & 0.888 & 0.390 \\
\hline & Week ${ }^{*}$ sex ${ }^{*}$ temperature & 5,124 & 1.684 & 0.152 \\
\hline \multirow[t]{7}{*}{ Great Tit } & Week & 5,96 & 14.079 & $<0.001$ \\
\hline & Sex & 1,96 & 0.017 & 0.896 \\
\hline & Temperature & 1,96 & 0.288 & 0.592 \\
\hline & Week* sex & 5,96 & 0.214 & 0.957 \\
\hline & Week * temperature & 5,96 & 0.827 & 0.530 \\
\hline & Sex ${ }^{*}$ temperature & 1,96 & 0.034 & 0.853 \\
\hline & Week ${ }^{*}$ sex $*$ temperature & 5,96 & 2.077 & 0.065 \\
\hline
\end{tabular}

\section{Individual differences in plasma LH trends}

Individual variation in the timing of peak plasma LH concentration was apparent in Eurasian Skylarks and Great Tits. In the Eurasian Skylark $15{ }^{\circ} \mathrm{C}$ group, maximum plasma LH concentrations were observed in one bird in the first week, one in the second week, two birds in the third week, six in the fourth week, and three in the fifth week (Fig. 2a). In the Eurasian Skylark $20^{\circ} \mathrm{C}$ group, three birds attained maximum plasma $\mathrm{LH}$ concentrations in each successive week after the first week (Fig. 2b). Individual variation among Great Tits was similar: in the $15{ }^{\circ} \mathrm{C}$ group, maximum plasma $\mathrm{LH}$ was attained by two birds in the first week, two birds in the second week, four birds in the fourth week, and two birds in the fifth week (Fig. 3a). In the $20{ }^{\circ} \mathrm{C}$ group, peak plasma LH was attained by three birds in the first week, two birds in the second week, two birds in the third week, one bird in the fourth week, and two birds in the fifth week (Fig. 3b).

\section{Discussion}

The LMM results indicate that temperature only significantly influenced the HPG axis activation of Eurasian Skylarks. Mean plasma LH of Eurasian Skylarks in the high temperature group was significantly higher than that of those in the low temperature group in the 1st, 2nd, and 3rd experimental week, suggesting that initiation of the HPG axis in this species can be advanced by higher temperature. Mean plasma LH in the Great Tit high temperature group was generally not significantly different to that in the low temperature group and the results of the LMM suggest that temperature had no effect on plasma LH. So far, researches on the influence of temperature 

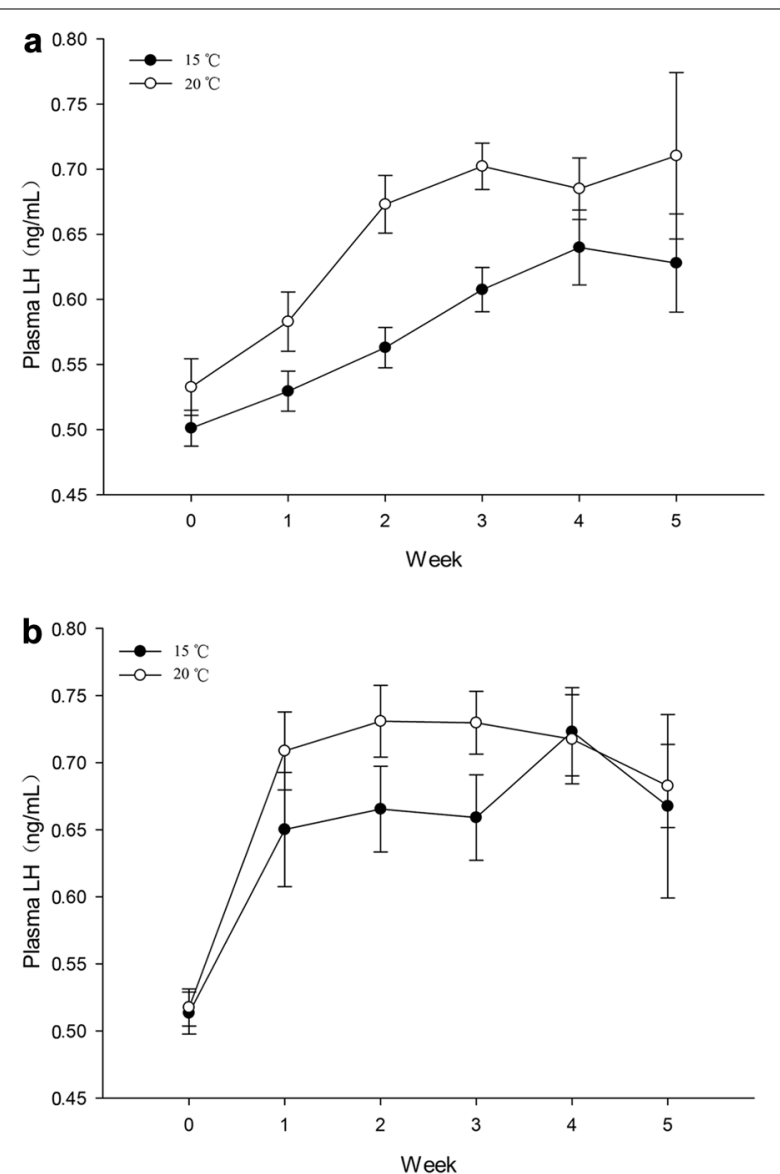

Fig. 1 The plasma LH level (mean \pm SD) of Eurasian Skylark (a) and Great Tit (b) during experimental exposure to a long photoperiod. $X$-axis is the number of treatment week on light-induced HPG endocrine process have obtained different results in different species, or in populations of same species living at different latitudes. For example, exposure to higher temperature did not influence lightinduced LH secretion in the White Crowned Sparrow (Wingfield and Sapolsky 2003), but did affect that of a southern European population of the Great Tit (Silverin et al. 2008). The results of previous studies and ours suggest that the effects of temperature on reproductive endocrine axis might differ among species; therefore, conclusions about the temperature effect on the activation of HPG axis should be concerned.

Our results shed light on the hypothesis that latitude may be an important factor contributing to this interspecies variation and that high latitude species display greater variation in the initiation of LH secretion with respect to temperature. There is some evidence that the degree of population decline caused by trophic mismatch is more pronounced in species that breed at lower latitudes (Jones and Cresswell 2010). This may be because
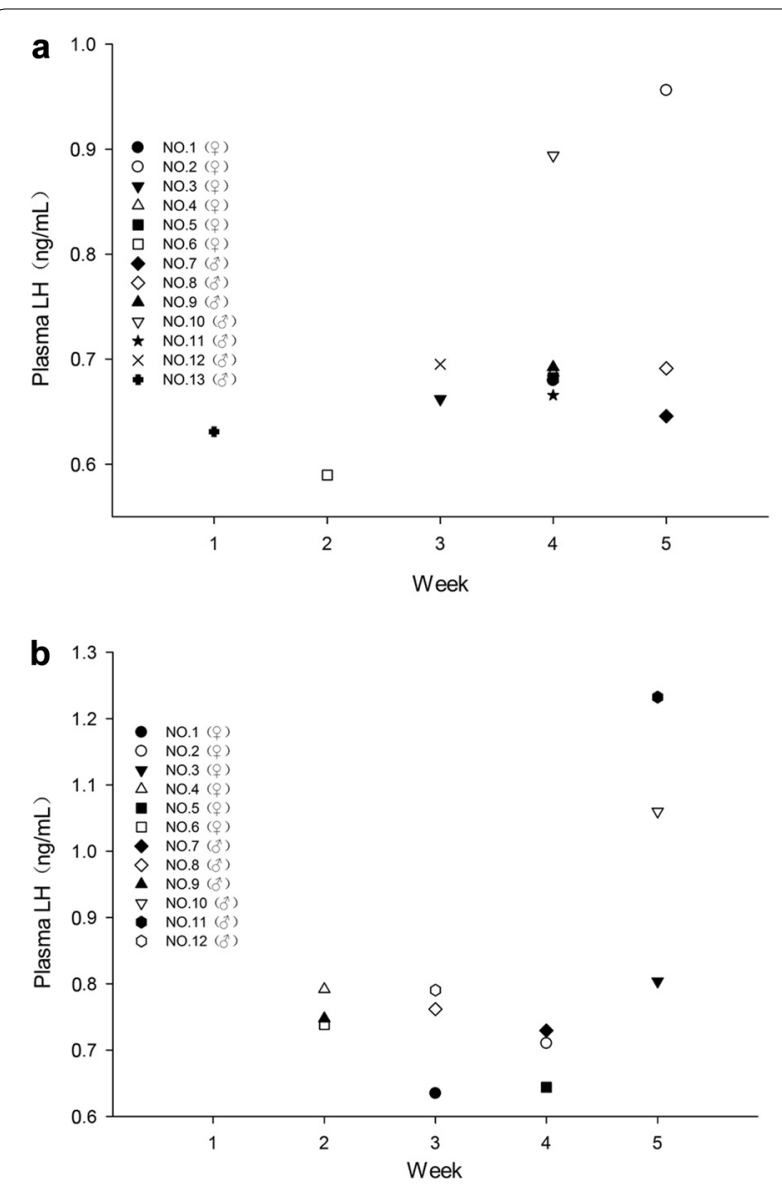

Fig. 2 The peak plasma LH level of the individual birds in $15^{\circ} \mathrm{C}(\mathbf{a})$ and $20^{\circ} \mathrm{C}(\mathbf{b})$ group of Eurasian Skylark. $X$-axis is the number of treatment week

temperature variation is less at lower latitudes and larger at higher latitudes. Bird populations at higher latitudes may have already undergone selection for plasticity in response to inter-annual variability in temperature (Charmantier et al. 2008). Our results provide possible physiological evidence for this hypothesis. The LH levels of the Eurasian Skylark, a high-latitude species, displayed high between-group variation, whereas the LH levels of the Great Tit, a mid latitude species, was relatively constant between groups. We suggest that more comparison studies among the species from different latitudes should be done in the future.

In contrast to previous studies, we also examined individual variation in the temporal pattern of $\mathrm{LH}$ response to temperature. We found marked individual variation in the timing of peak LH levels in both high and low temperature groups of Eurasian Skylarks and Great Tits. In Eurasian Skylarks and Great Tits, some members of both temperature treatment groups attained peak LH levels in the first or the second week of the experiment, suggesting 

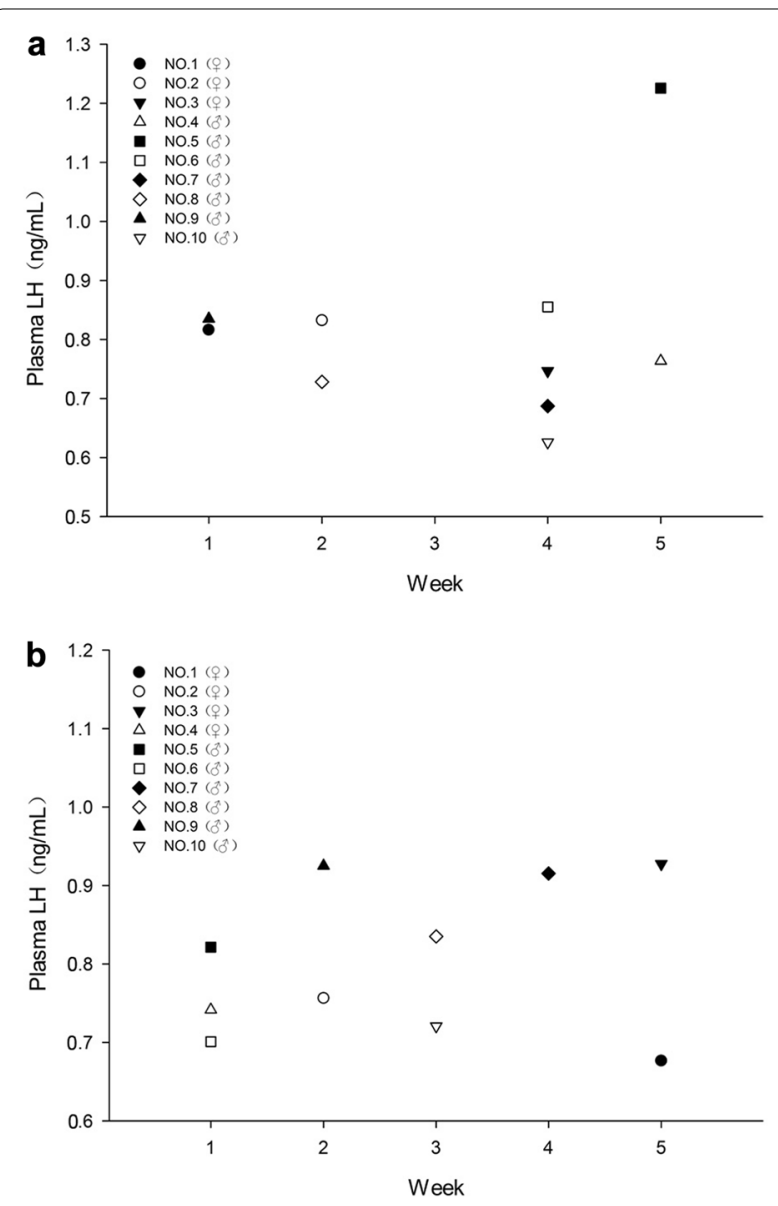

Fig. 3 The peak plasma LH level of the individual birds in $15^{\circ} \mathrm{C}(\mathbf{a})$ and $20^{\circ} \mathrm{C}(\mathbf{b})$ group of Great Tit

that some individuals in these species have the potential to advance the timing of reproduction, irrespective of whether they are in a low or high temperature environment. This suggests that the activation of reproductive endocrine axis is polymorphic in some species, and that this variation could allow the population to cope with the possible challenge of trophic mismatch caused by climate warming.

Recent research indicates that the average breeding dates of several bird species, such as Ultramarin Jays (Aphelocoma ultramarine; Brown et al. 1999), European Pied Flycatchers (Ficedula hypoleuca; Both et al. 2004; Both and Visser 2005), and Great Tits (Parus major; Both et al. 2004; Visser et al. 2006), have advanced from a few days to over a week, presumably as a result of ambient temperature increases and the subsequent earlier availability of insect food sources. However, the laying dates of populations of some species, such as a European population of the Collared Flycatcher (Ficedula albicollis; Przybylo et al. 2000), have not displayed a commensurate advance. Even in the European Pied Flycatcher, which has been found to breed earlier in response to an earlier peak in caterpillar abundance, some individuals still bred later with the result that their nestling period did not coincide with the period of peak food abundance (Both et al. 2006). Our finding that the timing of reproductive endocrine axis activation is more flexible in individuals of some species than in others provides a potential physiological explanation for the above phenomenon. Individual variation in peak $\mathrm{LH}$ within populations may allow some individuals to breed earlier, thereby synchronizing breeding with peak food abundance. Therefore, species with either greater physiological plasticity in response to temperature, or that are more polymorphic with respect to the timing of breeding, may be better able to adjust their breeding dates in response to climate change, whereas species without these characteristics may be unable to synchronize their breeding with earlier peaks in food abundance.

Although individual variation in the activation of LH secretion is apparent in populations of some species, it remains to be determined if all such variation has a genetic basis. Circadian Locomotor Output Cycles Kaput (CLOCK) is a highly conserved transcription factor central to the rhythmicity of the circadian oscillator (Bourret and Garant 2015). The Clock gene possesses a poly-glutamine (poly-Q) binding region that is polymorphic in length (the number of $Q$ repeats), which affects its binding affinity to its transcription factor (Darlington et al. 1998). Variation in Clock gene poly-Q length has been found to be related to both breeding site latitude (Johnsen et al. 2007) and breeding phenology (Liedvogel et al. 2009; Caprioli et al. 2012). The relationship between the timing of HPG axis activation and likely candidate genes should be investigated in the future. Furthermore, the relationship between HPG endocrine process and reproductive parameters, such as laying date and fledgling period, should be examined to confirm the ecological effects of any observed physiological polymorphism.

\section{Conclusions}

According to our results, we conclude that the effects of temperature on reproductive endocrine axis differ among species. Seasonal activation of the HPG axis in the high-latitude species can be advanced by higher temperature. Meanwhile the activation of reproductive axis is polymorphic in some species. Species with either greater physiological plasticity in response to temperature, or that are more polymorphic with respect to the timing of breeding, may be better able to adjust their breeding dates in response to climate change, whereas species without these characteristics may be unable to synchronize their breeding with earlier peaks in food abundance. 


\section{Additional file}

Additional file 1: Figure S1. The dose-response curves for $\mathrm{LH}$ of chicken, Eurasian Skylark and Great Tit.

\section{Authors' contributions}

SZ conceived the study and designed the experiments. LG and JG conducted the experiments. LG wrote the first draft of the article. SZ supervised the research and revised the draft. All authors read and approved the final manuscript.

\section{Acknowledgements}

We are grateful to Professor Jinsong Liu and Professor Weihong Zheng in Wenzhou University for their help on the experiment treatment.

\section{Competing interests}

The authors declare that they have no competing interests.

\section{Availability of data and materials}

The data used in the present study are available from the corresponding author on reasonable request.

\section{Consent for publication}

Not applicable.

\section{Ethical statement}

Our experimental procedures complied with the current laws on animal welfare and research in China and had the approval of the Animal Research Ethics Committee of Hainan Normal University. In addition, all procedures followed standard protocols, such as the ARRIVE guidelines for reporting animal research.

\section{Funding}

This study was supported by the National Natural Science Foundation of China (No. 31372225), Fund of Minzu University of China (No. ydzxxk201619), and "111" Project (2008-B0844)

Received: 6 June 2017 Accepted: 1 January 2018

Published online: 12 January 2018

\section{References}

Ball G, Balthazart J. Individual variation and the endocrine regulation of behavior and physiology in birds: a cellular/molecular perspective. Philos Trans R Soc B. 2008:363:1699-710.

Both C, Artemyev AV, Blaauw B, Cowie RJ, Dekhuijzen AJ. Large-scale geographical variation confirms that climate change causes birds to lay earlier. Proc R Soc B. 2004;271:1657-62.

Both C, Visser ME. The effect of climate change on the correlation between avian life-history traits. Globle Change Biol. 2005;11:1606-13.

Both C, Bouwhuis S, Lessells C, Visser M. Climate change and population declines in a long-distance migratory bird. Nature. 2006;441:81-3.

Both C, van Turnhout C, Bijlsma R, Siepel H, van Strien A, Foppen R. Avian population consequences of climate change are most severe for longdistance migrants in seasonal habitats. Proc Biol Sci. 2010;277:1259-66.

Bourret A, Garant D. Candidate gene-environment interactions and their relationships with timing of breeding in a wild bird population. Ecol Evol. 2015:5:3628-41.

Brown JL, Li SH, Bhagabati N. Long-term trend toward earlier breeding in an American bird: a response to global warming. Proc Natl Acad Sci USA. 1999;96:5565-9.

Caprioli M, Ambrosini R, Boncoraglio G, Gatti E, Romano A, Romano M, Rubolini D, Gianfranceschi L, Saino N. Clock gene variation is associated with breeding phenology and maybe under directional selection in the migratory barn swallow. PLoS ONE. 2012;7:e35140.
Charmantier A, McCleery R, Cole L, Perrins C, Kruuk L, Sheldon B. Adaptive phenotypic plasticity in response to climate change in a wild bird population. Science. 2008:320:800-3.

Chastel O, Barbraud C, Weimerskirch H, Lormée H, Lacroix A, Tostain O. High levels of $\mathrm{LH}$ and testosterone in a tropical seabird with an elaborate courtship display. Gen Comp Endocrinol. 2005;140:33-40.

Cotton P. Avian migration phenology and global climate change. Proc Natl Acad Sci USA. 2003;100:12219-22

Darlington TK, Wager-Smith K, Ceriani MF, Staknis D, Gekakis N, Steeves TDL, Weitz CJ, Takahashi JH, Kay SA. Closing the circadian loop: CLOCKinduced transcription of its own inhibitors per and tim. Science. 1998;280:1599-603.

Dawson A. The effect of temperature on photoperiodically regulated gonadal maturation, regression and moult in starlings_-potential consequences of climate change. Funct Ecol. 2005;19:995-1000.

Dawson A. Control of the annual cycle in birds: endocrine constraints and plasticity in response to ecological variability. Philos Trans R Soc B. 2008:363:1621-33.

Dawson A, King V, Bentley G, Ball G. Photo-periodic control of seasonality in birds. J Biol Rhythm. 2001;16:365-80.

Griffith SC, Stewart IRK, Dawson DA, Owens IPF, Burke T. Contrasting levels of extra-pair paternity in mainland and island populations of the house sparrow (Passer domesticus): is there an "island effect"? Biol J Linn Soc. 1999;68:303-16.

Gullett P, Hatchwell B, Robinson R, Evans K. Phenological indices of avian reproduction: crypticshifts and prediction across large spatial and temporal scales. Ecol Evol. 2013:3:1864-77.

Gwinner E. Circannual rhythms in birds. Curr Opin Neurobiol. 2003;13:770-8

Johnsen A, Fidler A, Kuhn S, Carter K, Hoffmann A, Barr I. Avian clock gene polymorphism: evidence for a latitudinal cline in allele frequencies. Mol Ecol. 2007:16:4867-80.

Jones T, Cresswell W. The phenology mismatch hypothesis: are declines of migrant birds linked to uneven global climate change? J Anim Ecol. 2010;79:98-108.

Liedvogel M, Szulkin M, Knowles S, Wood M, Sheldon B. Phenotypic correlates of clock gene variation in a wild blue tit population: evidence for a role in seasonal timing of reproduction. Mol Ecol. 2009;18:2444-56.

Pawson AJ, McNeilly AS. The pituitary effects of GnRH. Anim Reprod Sci. 2005;88:75-94.

Przybylo R, Sheldon B, Merila J. Climatic effects on breeding and morphology: evidence for phenotypic plasticity. J Anim Ecol. 2000;69:395-403.

Silverin B, Wingfield J, Stokkan K, Massa R, Järvinen A, Andersson N, Lambrechts $M$, Sorace A, Blomqvist D. Ambient temperature effects on photo induced gonadal cycles and hormonal secretion patterns in great tits from three different breeding latitudes. Horm Behav. 2008;54:60-8.

Visser ME, Holleman L, Gienapp P. Shifts in caterpillar biomass phenology due to climate change and its impact on the breeding biology of an insectivorous bird. Oecologia. 2006;147:164-72.

Visser ME, Te Marvelde L, Lof ME. Adaptive phenological mismatches of birds and their food in a warming world. J Ornithol. 2012;153:S75-84.

Williams T. Individual variation in endocrine systems: moving beyond the 'tyranny of the Golden Mean'. Philos Trans R Soc B. 2008;363:1687-98.

Wingfield JC. Control of testicular cycles in the song sparrow, Melospiza melodia: interaction of photoperiod and an endogenous program? Gen Comp Endocrinol. 1993:92:388-401.

Wingfield JC, Sapolsky RM. Reproduction and resistance to stress: when and how. J Neuroendocrinol. 2003:15:711-24.

Wingfield JC, Hahn T, Levin R, Honey P. Environmental predictability and control of gonadal cycles in birds. J Exp Zool. 1992;261:214-31.

Wingfield JC, Hahn TP, Wada M, Schoech S. Effects of day length and temperature on gonadal development, body mass, and fat depots in white-crowned sparrows, Zonotrichia leucophrys pugetensis. Gen Comp Endocrinol. 1997;107:44-62

Wingfield JC, Hahn T, Maney D, Schoech S, Wada M, Morton M. Effects of temperature on photoperiodically induced reproductive development, circulating plasma luteinizing hormone and thyroid hormones, body mass, fat deposition and molt in mountain white-crowned sparrows, Zonotrichia leucophrys oriantha. Gen Comp Endocrinol. 2003;131:143-58.

Yamamura T, Yasuo S, Hirunagi K, Ebihara S, Yoshimura T. T3 implantation mimics photoperiodically reduced encasement of nerve terminals by 
glial processes in the median eminence of Japanese quail. Cell Tissue Res. 2006;324:175-9.

Zhang S, Chen X, Zhang J, Li H. Differences in the reproductive hormone rhythm of tree sparrows (Passer montanus) from urban and rural sites in Beijing: the effect of anthropogenic light sources. Gen Comp Endocrinol. 2014;206:24-9.
Zhao L, Gao L, Yang W, Xu X, Wang W, Liang W, Zhang S. Do migrant and resident species differ in the timing of increases in reproductive and thyroid hormone secretion and body mass? A case study in the comparison of pre-breeding physiological rhythms in the Eurasian Skylark and Asian Short-toed Lark. Avian Res. 2017;8:10-9.

\section{Submit your next manuscript to BioMed Central and we will help you at every step:}

- We accept pre-submission inquiries

- Our selector tool helps you to find the most relevant journal

- We provide round the clock customer support

- Convenient online submission

- Thorough peer review

- Inclusion in PubMed and all major indexing services

- Maximum visibility for your research

Submit your manuscript at

www.biomedcentral.com/submit 